\title{
THE INFLUENCE OF ROOT CANAL TAPER AND CURVATURE ON THE STRESSES GENERATED DURING VERTICAL COMPACTION OBTURATION TECHNIQUE
}

\author{
Enas Mahmoud Moustafa Sanad*, Ghada El-Hilally Eid ${ }^{* * *}$ and Hebatallah Mohamed Maged El-Far ${ }^{* * *}$
}

\begin{abstract}
Objective: The aim of this study was to evaluate the effect of different taper on stresses generated within root canals that have varying degree of curvature when subjected to vertical compaction obturation technique.

Methods: Thirty extracted teeth were divided into three groups, group1: teeth with straight roots, group 2: teeth with moderate curvature roots, group3: teeth with severe curvature. Each group was divided into two subgroups: A or B according to the preparation taper of root canal either $2 \%$ or $6 \%$ taper. Molds were constructed to simulate the presence of root within artificial socket, then vertical compaction obturation technique is performed with force equal to $1 \mathrm{~kg}$ at three levels apical, middle and coronal, then the samples were subjected to loading up to fracture.
\end{abstract}

Results: The result showed that there is no significance difference between the mean of fracture load of straight, moderate and severe curvature among the same group taper but $6 \%$ groups showed higher fracture resistance than $2 \%$ taper groups.

Conclusion: Increasing the canal taper will decrease the internal stresses within the root canal

KEY WORDS: Vertical root fracture, root canal curvature, root canal taper, vertical compaction technique, root canal stresses.

\section{INTRODUCTION}

Vertical root fracture (VRF) defined as longitudinal fracture of the root from the apex till the coronal part. It usually occurs in endodontically treated teeth. ${ }^{1}$
The vertical fracture is a common reason for loss of endodontically treated teeth; ${ }^{2}$ it may involve the whole length of the root or only a section of it. It may involve only one or both sides of the root, most commonly in a buccolingual direction.

* Master Degree Dentist, Cairo University.

** Assistant Professor Endodontic Department, Cairo University.

*** Professor Endodontic Department, Cairo University. 
The clinical picture of VRF may resample periodontal disease or failed endodontic treatment of the tooth, the radiographic diagnosis of VRF is complicated as there are many factors affecting the radiographic diagnosis like angulations, contrast, and the density of conventional radiographic image. ${ }^{3}$ There are other aids helps in diagnosis of VRF like staining with dye, transillumination using fiberoptic light and surgical exposure of the root. ${ }^{4}$

Vertical root fracture may occur in any phase of endodontic treatment: access cavity preparation, instrumentation, obturation or even during post placement. ${ }^{5,6}$

The risk of root fracture may be increased if an extra force is applied during vertical or lateral condensation obturation technique. ${ }^{7}$

Canal preparation involves dentin removal may compromise the fracture strength of the roots; as it may lead to root cracks, therefore, another cause of VRF. ${ }^{8-10}$

The recent evolution of root canal preparation techniques with introduction of rotary nickeltitanium (Ni-Ti) instruments for canal preparation has changed canal shape, size, and taper compared to hand instrumentation. Canal shape after preparation with hand files can be quite irregular. From a fracture mechanics point of view, the presence of structural defects, cracks, or canal irregularities is likely to play a major role in determining fracture strength, because an applied stress may be exponentially amplified at the tip of those defects as the thinner dentine the more susceptibility to fracture. ${ }^{9}$ With rotary Ni Ti preparation, canal shapes are more likely to be rounder and smoother canal irregularities are likely to be incorporated into the preparation and eliminated. Theoretically, smoothly tapering canals prepared using rotary Ni-Ti should result in higher fracture strength.

Because the stresses predisposing to VRF are considered to be generated within the canal space, the pattern of stress distribution on the root canal surface is likely to be critical in directing crack initiation and fracture propagation.

Therefore the present study will evaluate the stresses created in curved root canals which may leads to vertical root fracture as result of different root canal taper and curvature.

\section{MATERIALS AND METHODS}

\section{Teeth selection and grouping}

Thirty extracted teeth were disinfected by sodium hypochlorite (5.25\% for 1 hour) and stored in saline until time to be used. The teeth were divided into three groups (10 teeth in each group) according to degree of curvature as the following:

Group 1: teeth having straight roots.

Group 2: teeth having moderate curvature roots ranged ( 20 - 36 degree).

Group 3: teeth having severed curvature roots ranged (more than 36 degree).

Preoperative radiograph was taken for each tooth to determine the root curvature according to Schneider method. ${ }^{(11)}$

\section{Root canal preparation}

All selected teeth were decoronated by TR 13 high speed tapered with round end stone. Working length was determined for each tooth by introducing file size 15 to root canal till it reach the apical foramen, then decreasing $1 \mathrm{~mm}$ from the measured length. Each group was divided into two subgroups (A and B) according to preparation taper of the root canal.

Subgroup A: the teeth were prepared with $2 \%$ taper rotary file (Thomas Helixofile, France) up to size 40 file till the full working length, then the coronal portion was prepared with gates glidden drills size 2 and 3 .

Subgroup B: prepared with $6 \%$ taper rotary files (NRT, Mani, UTSUNOMIYA TOCHIGI, Japan) up to size 40 (6\% taper) master apical file. 
In both subgroups, between each file the teeth were irrigated with $5.25 \%$ sodium hypochlorite (Clorox, Clorox Company, Egypt) and EDTA gel $15 \%$ (endo prep,cerkamed, Poland) was applied to the rotary file each time it was introduced into the canal.

Endo-Mate DT (NSK, Japan) endodontic rotary motor was used for root canal preparation with speed $250 \mathrm{RPM}$ and torque $1.8 \mathrm{Ncm}$.

\section{Mold construction}

All roots were wrapped with a single Aluminum foil till the cementoenamel junction. Then they were embedded in self cured composite resin mold to a level below cementoenamel junction by $4 \mathrm{~mm}$ to simulate artificial socket. After composite curing, the teeth were removed from mold and light body condensation silicon (speedex, Coltène Whaledent, Switzerland) was mixed according to manufacture instruction and was injected into artificial socket, afterwards the roots were placed into the simulated socket space.

\section{Obturation of the prepared root canal}

Three pluggers with suitable sizes were selected to compact gutta percha at three levels (apical, middle and coronal) using vertical compaction technique: The apical plugger was selected to reach $4 \mathrm{~mm}$ shorter than working length, while the coronal plugger had larger diameter without touching the root canal wall and intermediate size plugger was used to loosely fit the middle third of root canal. The canals were dried with paper points and Endofill (dentsply, parasail) sealer was applied to root canal by master cone. A master apical cone size 40 was cemented to full working length of root canal.

The gutta-percha was softened by heated heat carrier hand instrument. Pluggers were placed in the canal with apical pressure to produce a hydraulic force that moves the gutta-percha apically, against the canal walls. Gutta-percha was added in small increments; each increment of gutta-percha was heated and softened and packed vertically until the entire canal was filled. The vertical compaction was applied to the root canals at three levels apical, middle and coronal parts and compaction force was equal $1 \mathrm{~kg}$ as determined by placing the blocks on scale while obturation.

\section{Mechanical loading up to fracture}

Lloyd instrumental testing machine (UK) was used to apply vertical forces to the gutta percha in the root canal. Finger plugger size 40 or 60 (Mani, UTSUNOMIYA TOCHIGI, Japan), (40 for $2 \%$ taper, 60 for $6 \%$ taper) was connected to the machine and adjusted penetrate the root canal with speed of $0.5 \mathrm{~mm} / \mathrm{min}$. and to stop penetrating the obturated root canal when it reached $2 \mathrm{~mm}$ shorter than working length. The mold was centered under plugger and penetration started with gradual increase of penetration force. The fracture force $(\mathrm{N})$ value was determined from the graph then converted to Kg (Figure 1).

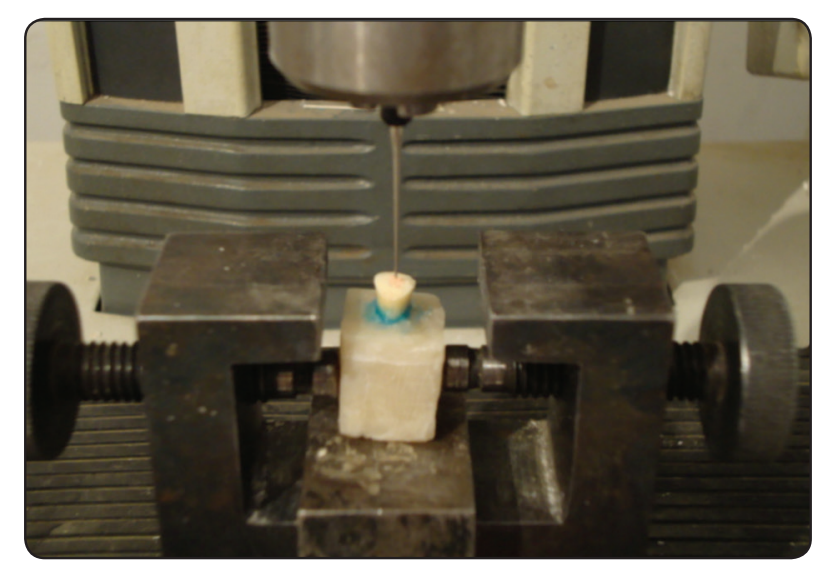

Fig. (1) Lloyd instrument testing machine (UK) when applying vertical force through finger plugger to an obturated root canal in composite mold up to fracture.

\section{Statistical Analysis}

Data was expressed as mean $\pm \mathrm{SD}$; comparing the mean of two groups was performed using the independent $t$-test. Comparing the mean of more than two groups was performed using One-way ANOVA (Analysis Of Variance). The significance level of $\alpha=0.05$ was used. 


\section{RESULTS}

The mean load at crack initiation for $2 \%$ taper prepared teeth was: straight root $13.14 \pm 0.65 \mathrm{~kg}$, moderate curvature root $9.84 \pm 0.24 \mathrm{Kg}$, and for severe curvature was $9.45 \pm 0.37 \mathrm{Kg}$ (Figure 2).

There was no statistical significant difference between the mean of fracture load of the straight, moderate and severe curvature roots among the $2 \%$ group $(\mathrm{P}>0.05)$.

The mean load at crack initiation for $6 \%$ taper prepared teeth was: $20.88 \pm 0.92 \mathrm{~kg}$ for straight roots, $11.37 \pm 0.26 \mathrm{~kg}$ for moderate curvature roots and $13.85 \pm 0.47 \mathrm{~kg}$ for severe curvature roots. There was no significant difference between the mean of the fracture load of the straight, moderate and severe curvature roots among the $6 \%$ group $(\mathrm{P}>0.05)$.

By comparing the different taper (2\% and $6 \%$ ) in each root curvature, $6 \%$ straight root had higher fracture resistance $(20.88 \pm 0.92 \mathrm{~kg})$ than $2 \%$ straight roots $(13.4 \pm 0.65 \mathrm{~kg})$.

$6 \%$ moderate curvature prepared roots had higher fracture resistance $(11.37 \pm 0.26 \mathrm{~kg})$ than $2 \%$ moderate curvature prepared roots $(9.84 \pm$ $0.24 \mathrm{~kg}$ ). $6 \%$ severe curvature prepared roots had higher fracture resistance $(13.85 \pm 0.47 \mathrm{~kg})$ than $2 \%$ prepared roots $(9.45 \pm 0.37 \mathrm{~kg})$. These differences were not statistically significant $(\mathrm{P}>0.05)$.

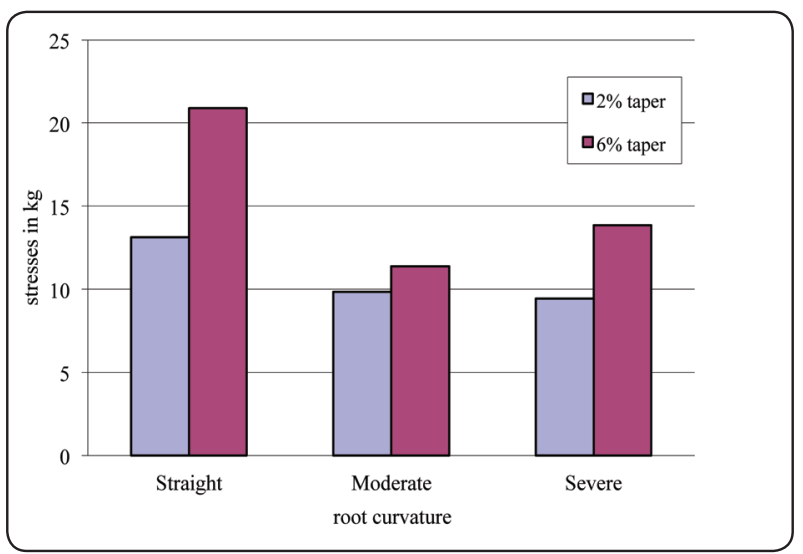

Fig. (2) Bar chart showing the mean values of stresses of the fracture load in $(\mathrm{Kg})$ of different groups (straight, moderate curvature and severe curvature roots) that prepared with either $2 \%$ or $6 \%$ taper.

\section{DISCUSSION}

Endodontically treated teeth can be subjected to stresses during root canal preparation and obturation. Many factors have been proposed as factors that potentially influence the fracture susceptibility, including extent of canal preparation, radius of canal curvature and external root morphology. ${ }^{12}$

In the present study, Teeth were selected to have different root curvature by measuring their angels of curvature on a buccal view of radiograph.

The teeth were prepared with different taper (either $2 \%$, or $6 \%$ ) to evaluate the effect of root canal taper on the fracture resistance of the root as Holcomb et al $1987^{13}$ found that there is significant correlation between the fracture load and root width, root canal width, canal taper, ratio of canal width and total root width, also Sathorn et al $2005^{14}$ found that preparing small ovoid canals will create a less degree of root curvature and will decrease the fracture susceptibility of the roots, Rundquist and Versluis $2006{ }^{15}$ reported that with the increase of root canal taper the root stresses decreased during root canal filling.

The increase of root canal taper (6 \%) that represent the resent trend in root canal instrumentation not only decrease the internal root stresses during root canal obturation but also has the ability to decrease the intra canal bacteria better than using smaller size instrument file. ${ }^{16,17}$

In this study we did not choose more than $6 \%$ taper in order to not reduce the fracture resistance of the root canal after debridement. ${ }^{18}$

In the present study, the obturation technique was performed under simulated condition with simulation of natural periodontal ligament and socket. The teeth were wrapped with single layer of aluminum foil ${ }^{9}$ which was later removed and replaced by condensation silicon impression material to allow simulation of periodontal ligament. While alveolar bone was simulated by chemical cure composite resin as it has modulus of elasticity 
near that of alveolar bone $(16,600 \mathrm{MPa})$ as reported by Chatvanitkul et al $2010 .{ }^{19}$

During mold construction, the roots were embedded to a level of $4 \mathrm{~mm}$ below cementoenamel junction. There was no composite collar to support the root during obturation as it may reinforce the root and cause higher fracture resistance of roots during testing as reported by Pitts et al 1983. ${ }^{20}$

We used vertical compaction technique as its forces may be equal to lateral condensation technique that may be potential for VRF. ${ }^{18}$

Obturation using vertical compaction was performed using scale to ensure standardized loading of $1 \mathrm{~kg}$ as this is within the safety range of compaction force during obturation $(1-3 \mathrm{~kg}$ ) as documented by Harvey et al 1981. ${ }^{21}$ Also Blum et al $1997^{22}$ revealed that vertical compaction loading should never to exceed $3 \mathrm{~kg}$. The finger plugger size was chosen such that it was not touching the canal wall to avoid the wedging effect of the plugger. ${ }^{22,23}$

During fracture testing, size 40 and 60 pluggers were chosen to load the $2 \%$ and $6 \%$ prepared teeth, respectively. The machine was adjusted such that it stops vertical loading when the plugger reaches $2 \mathrm{~mm}$ shorter than working length; to avoid root fracture due to wedging effect of the plugger. ${ }^{24}$ Bending of plugger was a problem faced in the testing. Each time the plugger was bent, it was replaced by the same plugger size to continue the test as advised by Hammas et al $2007^{25}$ who faced the same problem.

In this study we measured the fracture resistance of the obturated roots by applying external forces up to fracture, while Kumaran et al $2013{ }^{18}$ studied the roots directly after obturation without appling external forces as he aimed to study the dentinal defects and incomplete cracks which predispose vertical root fracture.

The main fracture load among the different three main groups ranged from $20.88 \mathrm{~kg}$ (6\% straight roots group) to $9.45 \mathrm{~kg}$ ( $2 \%$ sever curvature roots).
Soro et al reported different fracture load values which ranged from $17.2 \mathrm{~kg}$ to $6.2 \mathrm{~kg}$. ${ }^{24}$ The mean fracture load for straight roots prepared with $2 \%$ taper was $13.14 \mathrm{~kg}$ which were similar to results obtained by Pitts et al 1983. ${ }^{20}$

\section{CONCLUSION}

Increasing canal taper may help in protecting the prepared root canal from the generated stresses that induced within root canal during root canal obturation which may precede vertical root fracture.

\section{REFERANCES}

1. Saw LH, Messer HH. Root strain associated with different obturation techniques. J Endod 1995;21:314-20.

2. Caplan DJ, Weintraub JA. Factors related to loss of root canal filled teeth. J Public Health Dent 1997;57:31-9.

3. Khasnis SA, Kidiyoor KH, Patil AB, Kenganal SB. Vertical root fractures and their management. J Conser Dent 2014; 17: 103- 10.

4. Meister F, Lomme TJ, Gerstein H. Diagnosis and possible causes vertical root fracture. Oral Surg Oral Med Oral Pathol 1980;49:243-53.

5. Fuss Z, Lustig J, Katz A, Tamse A. An evaluation of endodontically treated vertical root fracture teeth: impact of operative procedure. J Endod 2000;65:287-92.

6. Tang W, Wu Y, Smales RJ. Identifying and reducing risks for potential fractures in endodontically treated teeth. J Endod 2010;36:609-17.

7. Zandbiglari T, Davids H, SchäferE. Influence of instrument taper on the resistance to fracture of endodontically treated roots. Oral surg Oral Med Oral Path Oral Radiol Endod 2006;101:126-31.

8. Adorno CG, Yoshioka T, Suda H. The effect of root preparation technique and instrumentation length on the development of apical root cracks. J Endod 2009;35: 389-92.

9. Wilcox LR, Rosekelly C, Sutton T. The relationship of root canal enlargement to finger-spreader induced vertical root fracture. J Endod 1997;23:533-34.

10. Bier CA1, Shemesh H, Tanomaru-Filho M, Wesselink PR, Wu MK. The ability of different nickel-titanium rotary instruments to induce dentinal damage during canal preparation. J Endod 2009;35:236-38. 
11. Schnieder W E. comparison of canal preparation in straight and curved root canals. Oral surg 1971;32:27-5.

12. Lertchirakarn V, Palamara J E, and Messer H H. Patterns of vertical root fracture: factors affecting stress distribution in the root canal. J Endod 2003;29: 523-28.

13. Holcomb Q, Pitts DL, Nichol JI. Further investigation of spreader loads required to cause vertical root fracture during lateral condensation. J Endod 1987;13:277- 84.

14. Sathorn C, Palamara JE, Palamara D, Messer HH. Effect of root canal size and external root surface morphology on fracture susceptibility and patterns: A finite element analysis. J Endod 2005;31:288-92.

15. Rundquist BD, Versluis A. How dose canal taper affect root stresses? Int Endod J 2006;39: 226-37.

16. Tan B, Messer H. The quality of apical canal preparation using hand and rotary instruments with specific criteria for enlargement based on initial apical file size. J Endod 2002;28:658-64.

17. Dalton BC, Orstavik D, Phillips C, Pettiette M, Trope M. Bacterial reduction with nickel-titanium rotary instrumentation. J Endod 1998;24:763-67.

18. Kumaran P, Sivapriya E, Indhramohan J, Gopikrishna V, Savadamoorthi KS, Pradeepkumar AR. Dentinal defects before and after rotary root canal instrumentation with three different obturation techniques and two obturating materials. J Conser Dent 2013;16:522-26.
19. Chatvanitkul C, Lertchirakarn V. Stress distribution with different restorations in teeth with curved roots: A finite element analysis study. J Endod 2010;36:115-18.

20. Pitts DL, Matheny JE, Nichol JI. An in vitro study of spreader loads required to cause vertical root fracture during lateral condensation. J Endod 1983;9:544-50.

21. Harvey TE, White TJ, Leeb IJ. Lateral condensation stress in root canals. J Endod 1981;7:151-55.

22. Blum JY, Parahy E, Micallef JP. Analysis of forces developed during obturation: Warm vertical compaction. J Endod 1997;23:91-5.

23. Ricks-Williamson LJ, Fotos PG, Goel VK, Spivey JD, Rivera EM, Khera SC. A three-dimensional finite-element stress analysis of an endodontically prepared maxillary central incisor. J Endod 1995;21:362-67.

24. Soros C, Zinelis S, Lambrianidis T, Palaghias G, Thessaloniki A. Spreader load required for vertical root fracture during lateral compaction ex vivo: evaluation of periodontal simulation and fracture load information. Oral Surg Oral Med Oral Pathol Oral Radiol Endod 2008; 106:e64- e70.

25. Hammad M, Qualtrough A, Silikas N. Effect of new obturating materials on vertical root fracture resistance of endodontically treated teeth. J Endod 2007;33:732-36. 